\title{
Can We Better Estimate Resting Oxygen Consumption by Incorporating Arterial Blood Gases and Spirometric Determinations?
}

\author{
Adriano R Tonelli MD, Xiao-Feng Wang PhD, Anara Abbay MD, Qi Zhang MSc, \\ José Ramos RRT, and Kevin McCarthy RPFT
}

\begin{abstract}
BACKGROUND: We hypothesize that oxygen consumption $\left(\dot{\mathrm{V}} \mathrm{O}_{2}\right)$ estimation in patients with respiratory symptoms is inaccurate and can be improved by considering arterial blood gases or spirometric variables. METHODS: For this retrospective study, we included consecutive subjects who underwent cardiopulmonary exercise testing. Resting $\dot{\mathrm{V}}_{2}$ was determined using breath-bybreath testing methodology. Using a training cohort $(n=336)$, we developed 3 models to predict $\dot{\mathrm{V}} \mathrm{O}_{2}$. In a validation group $(n=114)$, we compared our models with 7 available formulae. RESULTS: Our first model $\left(\dot{\mathrm{V}}_{2}=-184.99+189.64 \times\right.$ body surface area $\left[\mathrm{BSA}, \mathrm{m}^{2}\right]+1.49 \times$ heart rate $[$ beats $/ \mathrm{min}]+51.51 \times \mathrm{F}_{\mathrm{IO}_{2}}[21 \%=0 ; 30 \%=1]+30.62 \times$ gender $[$ male $=1$; female $=0]$ ) showed an $R^{2}$ of 0.5. Our second model $\left(\mathrm{V}_{O_{2}}=-208.06+188.67 \times \mathrm{BSA}+1.38 \times\right.$ heart rate $+35.6 \times$ gender $+2.06 \times$ breathing frequency [breaths/min]) showed an $R^{2}$ of 0.49 . The best $R^{2}(0.68)$ was obtained with our last model, which included minute ventilation $\left(\dot{\mathrm{V}} \mathrm{O}_{2}=-142.92+0.52 \times\right.$ heart rate $+126.84 \times \mathrm{BSA}+14.68 \times$ minute ventilation $[\mathrm{L}])$. In the validation cohort, these 3 models performed better than other available equations, but had wide limits of agreement, particularly in older individuals with shorter stature, higher heart rate, and lower maximum voluntary ventilation. CONCLUSIONS: We developed more accurate formulae to predict resting $\dot{\mathrm{V}}_{2}$ in subjects with respiratory symptoms; however, equations had wide limits of agreement, particularly in certain groups of subjects. Arterial blood gases and spirometric variables did not significantly improve the predictive equations. Key words: oxygen consumption; obstructive lung disease; restrictive lung disease; cardiopulmonary exercise; formula. [Respir Care 2015;60(4):517-525. (C) 2015 Daedalus Enterprises]
\end{abstract}

\section{Introduction}

The available equations to estimate oxygen consumption $\left(\dot{\mathrm{V}}_{2}\right)$ were obtained from selected populations (eg, children with congenital heart diseases) that commonly differ from the patients encountered in clinical practice (Table 1). More importantly, the estimates of resting $\dot{\mathrm{V}}_{2}$

Dr Tonelli, Mr Ramos, and Mr McCarthy are affiliated with the Department of Pulmonary, Allergy and Critical Care Medicine, Respiratory Institute, Cleveland Clinic; Dr Wang and Ms Zhang are affiliated with the Respiratory Institute Biostatistics Core, Quantitative Health Sciences, Cleveland Clinic; Dr Abbay is affiliated with the Medicine Institute, Cleveland Clinic, Cleveland, Ohio.

This publication was supported by CTSA KL2 grant TR000440 (to Dr Tonelli) from the National Center for Research Resources, a component of the National Institutes of Health, and by National Institutes of Health Roadmap for Medical Research. The authors have disclosed no other conflicts of interest. by the available formulae are inaccurate when compared with the $\dot{\mathrm{V}}_{2}$ directly measured either by the breath-tobreath methodology or Douglas bag technique combined with mass spectrometry. ${ }^{1}$ Due to these limitations, investigators have questioned the value of estimating $\dot{\mathrm{V}}_{2}$ and supported its direct measurement. ${ }^{2}$

Equations to estimate $\dot{\mathrm{V}}_{2}$ have not been systematically studied in patients with lung diseases or respiratory symptoms. It is possible that arterial blood gases and spirometric parameters may be of value to better predict the resting $\dot{\mathrm{V}}_{2}$ in patients with respiratory symptoms or diseases. We hypothesize that the estimation of $\mathrm{V}_{O_{2}}$ in patients with respiratory symptoms or diseases is inaccurate and that the

Correspondence: Adriano Tonelli MD, 9500 Euclid Avenue A-90, Cleveland, OH 44195. E-mail: tonella@ccf.org.

DOI: $10.4187 /$ respcare. 03555 


\section{Estimating OXYGEn CONSUMPTION}

predictive equations can be improved by adding parameters obtained from arterial blood gases and/or pulmonary function tests.

\section{Methods}

\section{Subject Selection and Study Design}

The research protocol was approved by the Cleveland Clinic institutional review board (study 13-1068). Written informed consent was waived. We included consecutive unique subjects who underwent cardiopulmonary exercise testing at the Pulmonary Function Test Laboratory of the Respiratory Institute, Cleveland Clinic, between October 2010 and September 2013. Cardiopulmonary exercise testing was ordered at the discretion of the treating physicians and was performed according to the American Thoracic Society/American College of Chest Physician recommendations. ${ }^{3}$ Common reasons for ordering the test included unexplained dyspnea and preoperative evaluation to better estimate the risk of surgery in subjects with lung diseases. We have not included patients with cardiovascular diseases because these individuals are tested by the Heart and Vascular Institute and are not captured in our database. Similarly, we did not include patients with known pulmonary hypertension, given that patients with this condition rarely undergo cardiopulmonary exercise testing at our laboratory.

Immediately before each cardiopulmonary exercise test, we measured height and weight, which were then used to calculate body surface area (BSA) by the equation of $\mathrm{Du}$ Bois et $\mathrm{al}^{4}$ :

$\mathrm{BSA}=0.007184$

$\times(\text { height in } \mathrm{cm})^{0.725} \times(\text { weight in } \mathrm{kg})^{0.425}$

Furthermore, we recorded information on smoking status, type and time of last meal, medications, reason for the test, and need for supplemental oxygen therapy. We measured blood pressure and heart rate. Immediately before the $\dot{\mathrm{V}}_{2}$ determination and per protocol, we performed spirometry following American Thoracic Society/European Respiratory Society recommendations ${ }^{5}$ and obtained arterial blood gases from the radial artery. We later collected data on the type and severity of lung disease, serum thyroid-stimulating hormone concentration, and echocardiographic measurements. We graded severity of air flow limitation following the recommendations of the Global Initiative for Chronic Obstructive Lung disease. ${ }^{6}$ Restrictive lung disease was considered present when spirometry showed $\mathrm{FEV}_{1}$ over forced vital capacity $\left(\mathrm{FEV}_{1} / \mathrm{FVC}\right) \geq 0.7$ and the total lung capacity was less than $80 \%$ of predicted. ${ }^{7}$ In case of unspecific spirometric findings or overlap (obstructive and

\section{QUICK LOOK}

\section{Current knowledge}

Equations to estimate oxygen consumption $\left(\mathrm{V}_{\mathrm{O}_{2}}\right)$ have not been systematically studied in patients with lung diseases or respiratory symptoms. When knowledge of $\dot{\mathrm{VO}}_{2}$ is important, direct measurement is typically recommended.

\section{What this paper contributes to our knowledge}

New formulae to predict $\dot{\mathrm{V}}_{2}$ in subjects undergoing cardiopulmonary exercise testing for respiratory symptoms were developed using $\mathrm{F}_{\mathrm{IO}_{2}}$, minute volume, and breathing frequency. Arterial blood gases and spirometric variables did not significantly improve predictive equations.

restrictive disease), we reported the predominant ventilatory defect, based on a comprehensive evaluation by the authors (ART and AA).

\section{$\dot{\mathbf{V}}_{\mathbf{2}}$ Determination}

Subjects were told to continue taking all medications and only eat a light meal on the day of the test $(>2 \mathrm{~h}$ before the test). All examinations were performed by experienced respiratory therapists. No sedatives were given. Room temperature was maintained at $70^{\circ} \mathrm{F}$. After an acclimatization phase, we measured $\dot{\mathrm{V}}_{2}$ over a period of 5 min at rest in sitting position. $\dot{\mathrm{V}}_{\mathrm{O}_{2}}$ was determined using the Ultima $\mathrm{CardiO}_{2}$ gas exchange analysis system (MGC Diagnostics, Saint Paul, Minnesota), which is commercially available and uses breath-by-breath testing methodology. All subjects breathed spontaneously using an adequately sized 7450 series V2 face mask (Hans Rudolph, Inc, Shawnee, Kansas) held in place by head gear. We used a polycarbonate plastic adapter (Hans Rudolph, Inc) to connect the preVent flow sensor (MGC Diagnostics) to the mask. We performed flow and gas calibration before each test. All pertinent information was uploaded to an Excel database.

In the event the subject was on continuous $\mathrm{O}_{2}$ therapy, we provided supplementary $\mathrm{O}_{2}$ with a $\mathrm{F}_{\mathrm{IO}_{2}}$ of $30 \%$, using a $30 \% \mathrm{O}_{2}$ tank and a $30 \mathrm{~L}$ nondiffusing gas bag made of multilayer polyethylene thermoplastic laminate with a layer of aluminum foil at the center (Hans Rudolph, Inc). Corrugated tubing connected the 3-way stopcock attached to the bag and the mouthpiece.

\section{Formulae for Estimating Resting $\dot{\mathrm{V}}_{2}$}

For the estimation of resting $\dot{\mathrm{V}}_{2}$, we used the formulae by Bergstra et al $\left.{ }^{8}\left(\mathrm{~V}_{2}[\mathrm{~mL} / \mathrm{min}]\right)=157.3 \times \mathrm{BSA}^{2} \mathrm{~m}^{2}\right]+$ 


\section{Estimating OXYGEn CONSUMPTION}

Table 1. Formulae to Estimate $\dot{\mathrm{V}}_{2}$

\begin{tabular}{|c|c|c|c|c|c|}
\hline & Age Group & Condition & Subjects $(n)$ & Sedation & $\dot{\mathrm{V}}_{2}$ determination \\
\hline Bergstra et $\mathrm{al}^{8}$ & $\begin{array}{l}\text { Children and adults } \\
\text { (range 1-84 y) }\end{array}$ & $\begin{array}{l}\text { Subjects undergoing } \\
\text { catheterization }\end{array}$ & 250 & Sedated & $\begin{array}{l}\mathrm{Q} \text { (dye dilution) } \times \mathrm{a}-\overline{\mathrm{v}} \\
\mathrm{O}_{2} \text { content }\end{array}$ \\
\hline Dehmer et $\mathrm{al}^{9}$ & Adults (range $21-75$ y) & $\begin{array}{l}\text { Subjects undergoing } \\
\text { catheterization }\end{array}$ & 108 & $53 \%$ received sedation & $\begin{array}{l}\text { Q (dye dilution or } \\
\text { thermodilution) } \times a-\overline{\mathrm{V}} \\
\mathrm{O}_{2} \text { content }\end{array}$ \\
\hline Krovetz et $\mathrm{al}^{10}$ & $\begin{array}{l}\text { Children and adults } \\
\text { (range } 2 \text { mo-20 y) }\end{array}$ & Healthy subjects & 75 & Not available & Different methods \\
\hline LaFarge et al ${ }^{11}$ & $\begin{array}{l}\text { Children and adults } \\
\text { (range } 3-40 \mathrm{y} \text { ) }\end{array}$ & $\begin{array}{l}\text { CHD undergoing } \\
\text { catheterization }\end{array}$ & 879 & Sedated & Douglas bag collection. \\
\hline Lindahl $^{12}$ & Children ( $1 \mathrm{~d}$ to $7 \mathrm{y})$ & $\begin{array}{l}\text { Need for different } \\
\text { surgeries }\end{array}$ & 38 & General anesthesia & Douglas bag collection. \\
\hline Lundell et al ${ }^{13}$ & $\begin{array}{l}\text { Children and adults } \\
\text { (range 3-36 y) }\end{array}$ & $\begin{array}{r}\text { CHD undergoing } \\
\text { catheterization }\end{array}$ & 272 & Sedated & Flow-through technique \\
\hline Wessel et $\mathrm{al}^{14}$ & $\begin{array}{l}\text { Children and adults } \\
\text { (range } 15 \mathrm{~d}-17 \mathrm{y})\end{array}$ & $\begin{array}{l}\text { CHD undergoing } \\
\text { catheterization }\end{array}$ & 98 & Sedated & Flow-through technique \\
\hline \multicolumn{6}{|c|}{$\begin{array}{l}\mathrm{V}_{2}=\text { oxygen consumption } \\
\mathrm{Q}=\text { cardiac output } \\
\mathrm{a}-\overline{\mathrm{v}}=\text { arterial-venous } \\
\mathrm{CHD}=\text { congenital heart disease }\end{array}$} \\
\hline
\end{tabular}

gender $[$ men $=10$ or women $=0]-\left[10.5 \times \log _{e}\right.$ age $]+$ 4.8), Dehmer et al $^{9}\left(\dot{\mathrm{V}}_{2}[\mathrm{~mL} / \mathrm{min}]=125\left[\mathrm{~mL} / \mathrm{min} / \mathrm{m}^{2}\right] \times\right.$ BSA $\left.\left[\mathrm{m}^{2}\right]\right)$, Krovetz et $\mathrm{al}^{10}\left(\mathrm{~V}_{\mathrm{O}_{2}}[\mathrm{~mL} / \mathrm{min}]=-35.6+\right.$ $1.39 \times$ height $[\mathrm{cm}]+0.84 \times$ weight $[\mathrm{kg}])$, LaFarge et al ${ }^{11}$ $\left(\dot{\mathrm{V}}_{2}[\mathrm{~mL} / \mathrm{min}]=138.1-\right.$ [gender $[$ men $=11.49$ or women $=17.04] \times \log _{\mathrm{e}}$ age $]+[0.378 \times$ heart rate $] \times$ BSA $\left.\left[\mathrm{m}^{2}\right]\right)$, Lindahl $^{12}\left(\dot{\mathrm{V}}_{2}[\mathrm{~mL} / \mathrm{min}]=4 \times\right.$ weight $[\mathrm{kg}]+35.8)$, Lundell et $\mathrm{al}^{13}\left(\dot{\mathrm{V}}_{2}[\mathrm{~mL} / \mathrm{min}]=157.9 \times\right.$ BSA $\left[\mathrm{m}^{2}\right]+0.79 \times$ heart rate -61.8$)$ for males or $\left(\dot{\mathrm{V}}_{2}\right.$ $[\mathrm{mL} / \mathrm{min}]=159 \times \mathrm{BSA}\left[\mathrm{m}^{2}\right]+0.77 \times$ heart rate -61.6$)$ for females, and Wessel et $\mathrm{al}^{14}\left(\dot{\mathrm{V}}_{2}[\mathrm{~mL} / \mathrm{min}]=[144.8 \times\right.$ BSA $\left.\left.\left[\mathrm{m}^{2}\right]\right]+5.6\right)$.

\section{Statistical Analysis}

Continuous data are presented as mean $\pm \mathrm{SD}$ or median (interquartile range) where appropriate. Categorical data are summarized as discrete values and percentages ( $n[\%])$. The data were randomly separated into training and testing cohorts at a ratio of 3:1. Although we randomly divided these 2 groups, it was expected that some variables would be statistically different between them, a fact that tests the $\dot{\mathrm{V}}_{2}$ predictive equations more rigorously. The training data were used to build the linear regression model. Univariate linear regression analyses were performed on all predetermined independent variables and the outcome of interest, that is, resting $\dot{\mathrm{V}}_{2}$ ( $\left.\mathrm{mL} / \mathrm{min}\right)$. We performed correlation analysis of the predictors to avoid multicollinearity in multivariate regression models. The algorithm by Kuhn ${ }^{15}$ was applied to find the minimal set of predictors, and we excluded variables that were highly correlated (cor- relation value $>0.8$ ). The remaining predictors whose $P$ values were $<.10$ in the univariate linear regression analyses were used for building the multivariate linear regression models. Stepwise variable selection procedure using Akaike information criterion ${ }^{16}$ was applied to identify the final multivariate models. Nonlinearity and interactions were explored in the model building process.

We built 3 multivariate models from the training dataset, as different sets of variables may be available to healthcare providers. The 3 models as well as 7 previous models in the literature were assessed in the testing (validation) dataset. The concordance correlation coefficients (CCC) between estimated and measured $\dot{\mathrm{V}}_{2}$ determinations ${ }^{17}$ were calculated to evaluate the performance among all models. CCC is a standardized coefficient that contains a measurement of precision (Pearson correlation coefficient) and accuracy (bias correction factor). It ranges between -1 and 1 ( 1 represents perfect agreement). We calculated the coefficient of variation $(100 \times \mathrm{SD} /$ mean $)$ as well as the median and interquartile range of the absolute and percentage (absolute difference $\times$ 100/measured $\dot{\mathrm{V}}_{2}$ ) difference between the measured and estimated resting $\dot{\mathrm{V}}_{2}$. Bland-Altman methodology ${ }^{18}$ was used to plot the percentage difference between measured and estimated $\dot{\mathrm{V}}_{2}$ against the measured $\dot{\mathrm{V}}_{2}$ (accepted standard). ${ }^{19}$ The mean difference and $95 \%$ limit of agreement are reported when appropriate. ${ }^{18}$ All $P$ values are 2-tailed, and a value of $<.05$ was considered significant. SPSS 20 (SPSS, Chicago, Illinois), MedCalc (Ostend, Belgium), and R studio software were employed for the analyses (R Project, Vienna, Austria). 


\section{Results}

\section{Overall Characteristics of the Study Population}

We included 450 subjects, of whom 336 subjects formed part of the training cohort (used to build the lineal regression models) and 114 of the validation group (used to test the proposed and available formulae to estimate $\dot{\mathrm{V}}_{2}$ ). Characteristics of the training and validation cohort are presented in Table 2.

\section{Building a Model to Predict $\dot{\mathrm{V}}_{2}$}

We determined the measured $\dot{\mathrm{V}}_{2}$ and $\dot{\mathrm{V}}_{2} / \mathrm{kg}$ for a large number of variables of interest (Table 3 ). On occasion, only $\dot{\mathrm{V}}_{2}$ or $\dot{\mathrm{V}}_{2} / \mathrm{kg}$ were significant between groups; however, we only focused in predicting the measured absolute $\dot{\mathrm{V}}_{\mathrm{O}_{2}}$ rather than $\dot{\mathrm{V}}_{2} / \mathrm{kg}$, because performing regression analysis on indexed values that are then transformed to absolute values can lead to errors due to regression to the mean. ${ }^{8}$

We identified several predictors that had a $P$ value $<.10$ on univariate linear regression analysis (gender, height, weight, BSA, smoking status, heart rate, breathing frequency, $\mathrm{F}_{\mathrm{IO}_{2}}$, hemoglobin concentration, $\mathrm{O}_{2}$ content, lactic acid concentration, $\mathrm{FVC}, \mathrm{FEV}_{1}, \mathrm{FEV}_{1} / \mathrm{FVC}$, maximum voluntary ventilation $[\mathrm{MVV}]$, severity of obstructive or restrictive lung disease, and minute ventilation).

After correlation analyses, we removed arterial oxygen content, $\mathrm{FEV}_{1} \%$ of predicted, FVC percentage of predicted, and measured MVV. We kept BSA instead of height and/or weight, because BSA was preferentially selected by our models.

Our initial model (model 1) to estimate resting $\dot{\mathrm{V}}_{2}$ used all the variables with the exception of minute ventilation, as this determination requires especial equipment. After stepwise selection, we obtained the following equation $\left(\dot{\mathrm{V}}_{2}=-184.99+189.64 \times \mathrm{BSA}\left[\mathrm{m}^{2}\right]+1.49 \times\right.$ heart rate $[$ beats $/ \mathrm{min}]+51.51 \times \mathrm{F}_{\mathrm{IO}_{2}}[21 \%=0 ; 30 \%=1]+$ $30.62 \times$ gender $[$ male $=1$; female $=0])$. The $\mathrm{R}^{2}$ for this model was 0.5 (adjusted $\mathrm{R}^{2}$ : 0.49 ); therefore, this combination of predictive variables explained half of the variance of $\dot{\mathrm{V}}_{2}$. Multivariate adaptive regression splines made the model more complex by creating splines with 2 knots for heart rate and BSA without improving the $\mathrm{R}^{2}$.

Given that the criteria for using an $\mathrm{F}_{\mathrm{IO}_{2}}$ of $30 \%$ may vary among institutions, we developed a model (model 2) without this variable. In this case, the equation that best estimated resting $\dot{\mathrm{V}}_{2}$ (model 2) was: $-208.06+188.67 \times$ BSA $\left(\mathrm{m}^{2}\right), 1.38 \times$ heart rate (beats/min) $+35.6 \times$ gender $($ male $=1$; female $=0]+2.06 \times$ breathing frequency (breaths/min). The $\mathrm{R}^{2}$ for this equation was 0.49 (adjusted $\mathrm{R}^{2}$ : 0.48).
Table 2. Characteristics of the Testing and Validation Cohorts

\begin{tabular}{|c|c|c|c|}
\hline Characteristics & $\begin{array}{l}\text { Validation } \\
\text { Cohort }\end{array}$ & $\begin{array}{l}\text { Testing } \\
\text { Cohort }\end{array}$ & $P$ \\
\hline Subjects $(n)$ & 336 & 114 & \\
\hline Age (y) & $52 \pm 17$ & $52 \pm 18$ & .78 \\
\hline Height (cm) & $170 \pm 10$ & $168 \pm 10$ & .12 \\
\hline Weight (kg) & $83 \pm 22$ & $81 \pm 21$ & .28 \\
\hline $\operatorname{BSA}\left(\mathrm{m}^{2}\right)$ & $1.93 \pm 0.3$ & $1.90 \pm 0.3$ & .18 \\
\hline Female gender $(\%)$ & $167(50)$ & $71(62)$ & .02 \\
\hline White race $(\%)$ & $299(89)$ & $103(90)$ & .86 \\
\hline Smoking status (current) & $32(10)$ & $10(9)$ & .90 \\
\hline \multicolumn{4}{|l|}{ Reasons for testing } \\
\hline Unexplained dyspnea & $217(65)$ & $75(66)$ & \multirow[t]{4}{*}{.66} \\
\hline Preoperative & $90(27)$ & $31(27)$ & \\
\hline Asthma/VCD & $8(2)$ & $4(3)$ & \\
\hline Other & $21(6)$ & $4(3)$ & \\
\hline \multicolumn{4}{|l|}{ Spirometry } \\
\hline Normal & $193(60)$ & $61(57)$ & \multirow[t]{3}{*}{.70} \\
\hline Obstructive & $79(25)$ & $31(29)$ & \\
\hline Restrictive & $49(15)$ & $16(15)$ & \\
\hline \multicolumn{4}{|l|}{$\begin{array}{l}\text { Severity of obstructive } \\
\text { lung disease }\end{array}$} \\
\hline Mild & $14(18)$ & $7(23)$ & \multirow[t]{4}{*}{.37} \\
\hline Moderate & $32(41)$ & $7(23)$ & \\
\hline Severe & $21(27)$ & $11(36)$ & \\
\hline Very severe & $12(15)$ & $6(19)$ & \\
\hline Heart rate (beats/min) & $83 \pm 16$ & $82 \pm 15$ & .57 \\
\hline $\begin{array}{l}\text { Breathing frequency } \\
\text { (breaths/min) }\end{array}$ & $17 \pm 5$ & $17 \pm 5$ & .78 \\
\hline LVEF (\%) & $61 \pm 9$ & $61 \pm 6$ & .89 \\
\hline RVSP (mm Hg) & $29 \pm 11$ & $30 \pm 11$ & .73 \\
\hline TSH (mU/L) & $2.3 \pm 1.4$ & $2.6 \pm 2.2$ & .39 \\
\hline $\mathrm{pH}$ & $7.42 \pm 0.02$ & $7.43 \pm 0.04$ & .22 \\
\hline $\mathrm{P}_{\mathrm{aCO}_{2}}(\mathrm{~mm} \mathrm{Hg})$ & $37.9 \pm 4.3$ & $36.9 \pm 4.9$ & .06 \\
\hline $\mathrm{P}_{\mathrm{aO}_{2}}(\mathrm{~mm} \mathrm{Hg})$ & $87.9 \pm 11.0$ & $89.7 \pm 13.1$ & .20 \\
\hline Lactic acid (mmol/L) & $1.1 \pm 0.6$ & $1.1 \pm 0.7$ & .89 \\
\hline Hemoglobin (g/dL) & $13.8 \pm 2.1$ & $13.7 \pm 2.8$ & .83 \\
\hline $\mathrm{F}_{\mathrm{IO}_{2}}(\%)$ & $21.7 \pm 2.4$ & $21.9 \pm 2.8$ & .36 \\
\hline FVC (L/min) & $3.5 \pm 1.2$ & $3.4 \pm 1.1$ & .41 \\
\hline FVC (\% of predicted) & $85 \pm 18$ & $87 \pm 19$ & .49 \\
\hline $\mathrm{FEV}_{1}(\mathrm{~L} / \mathrm{min})$ & $2.6 \pm 1.1$ & $2.5 \pm 1.0$ & .45 \\
\hline $\mathrm{FEV}_{1}(\%$ of predicted $)$ & $80 \pm 23$ & $81 \pm 25$ & .77 \\
\hline $\mathrm{FEV}_{1} / \mathrm{FVC}$ & $0.74 \pm 0.15$ & $0.73 \pm 0.17$ & .65 \\
\hline MVV (L/min) & $107 \pm 47$ & $106 \pm 44$ & .81 \\
\hline Minute ventilation (L) & $12.3 \pm 3.5$ & $11.6 \pm 3.1$ & .06 \\
\hline$\dot{\mathrm{V}}_{2}$ & $326 \pm 91$ & $307 \pm 84$ & .04 \\
\hline$\dot{\mathrm{V}}_{2} / \mathrm{kg}$ & $4.0 \pm 1.0$ & $3.9 \pm 1$ & .24 \\
\hline $\begin{array}{l}\text { Data for cohorts are given as me } \\
\text { square. } \\
\text { BSA = body surface area } \\
\text { VCD = vocal cord dysfunction } \\
\text { LVEF = left ventricular ejection } \\
\text { RVSP = right ventricular systolic } \\
\text { TSH = thyroid-stimulating horm } \\
\text { MVV = maximum voluntary ven } \\
\mathrm{VO}_{2}=\text { oxygen consumption }\end{array}$ & $\mathrm{SD}$ or $n(\%) . P$ valu & re determined by & i chi \\
\hline
\end{tabular}




\section{Estimating OXYGEn CONSUMPTION}

Table 3. $\quad \dot{\mathrm{V}}_{2}$ and $\dot{\mathrm{V}} \mathrm{O}_{2} / \mathrm{kg}$ Measured in Different Subgroups of Interest

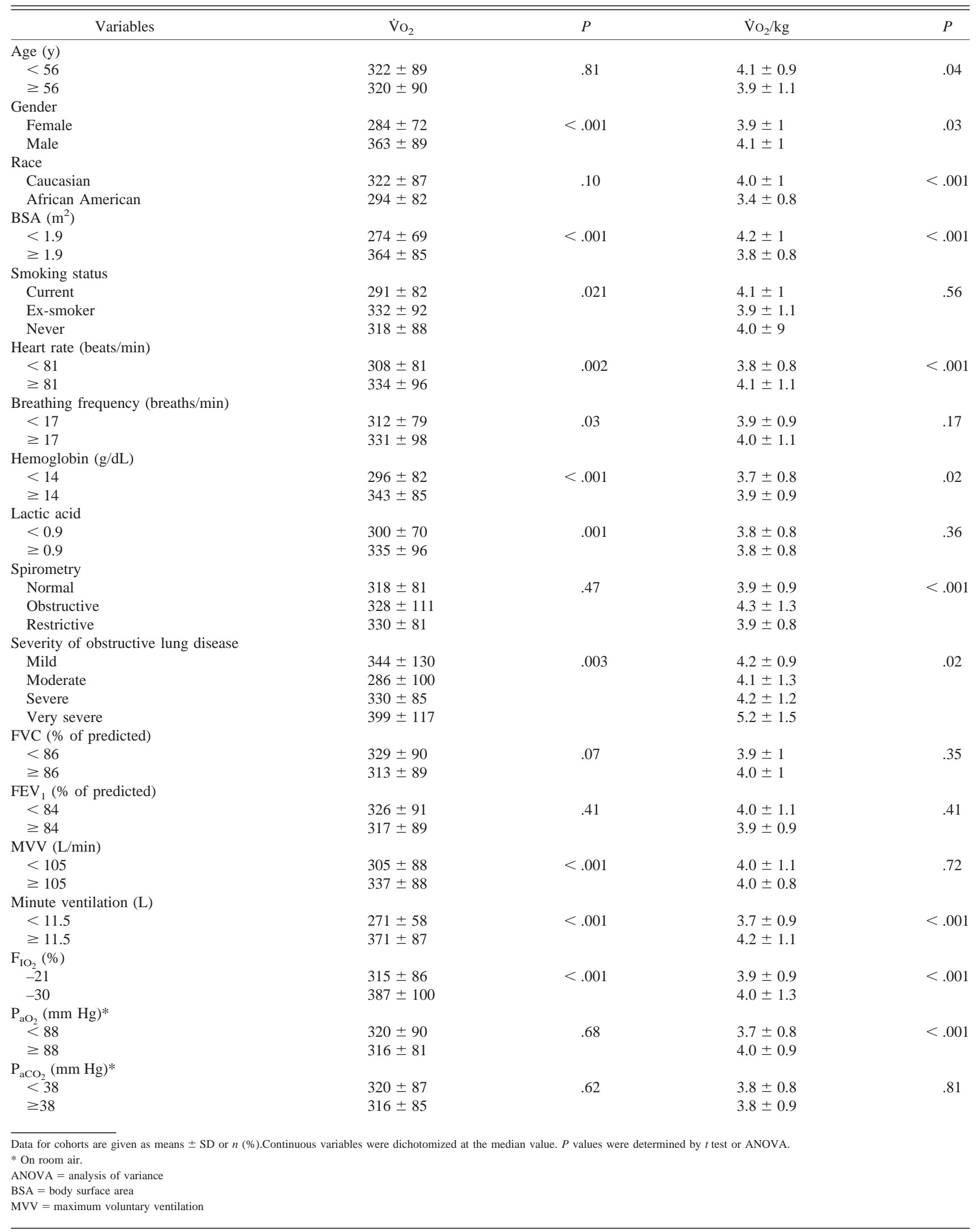


Estimating Oxygen Consumption

Table 4. Comparison of Different Models That Predict $\dot{\mathrm{V}}_{2}$ (Validation Cohort)

\begin{tabular}{|c|c|c|c|c|c|c|}
\hline Model & $\mathrm{CCC}$ & $95 \% \mathrm{CI}$ & $\begin{array}{l}\text { Coefficient of } \\
\text { Variation (\%) }\end{array}$ & $\begin{array}{l}\text { Absolute } \\
\text { Difference }\end{array}$ & $\begin{array}{l}\text { Percentage } \\
\text { Difference }\end{array}$ & $\begin{array}{l}\text { Percentage of Values } \\
\text { Differing }>25 \%\end{array}$ \\
\hline Model 1 & 0.71 & $0.62-0.79$ & 12.9 & $-16(-43$ to 19$)$ & $-6(-15$ to 6$)$ & 16 \\
\hline Model 2 & 0.65 & $0.54-0.74$ & 14.5 & $-18(-46$ to 18$)$ & $-6(-17$ to 5$)$ & 16 \\
\hline Model 3 & 0.72 & $0.63-0.80$ & 13.2 & $-8(-39$ to 18$)$ & $-3(-13$ to 6$)$ & 18 \\
\hline Bergstra et $\mathrm{al}^{8}$ & 0.45 & $0.35-0.55$ & 18.7 & 25 (1.6 to 75$)$ & $8(1$ to 21$)$ & 22 \\
\hline Dehmer et $\mathrm{al}^{9}$ & 0.28 & $0.20-0.35$ & 25.1 & 57 (25 to 108$)$ & 19 (10 to 30$)$ & 41 \\
\hline Krovetz et $\mathrm{al}^{10}$ & 0.32 & $0.25-0.40$ & 19.7 & $27(-3$ to 72$)$ & $9(-1$ to 21$)$ & 23 \\
\hline LaFarge et al ${ }^{11}$ & 0.27 & $0.20-0.35$ & 30.8 & 77 (50 to 124$)$ & 28 (19 to 35$)$ & 67 \\
\hline Lindahl $^{12}$ & 0.50 & $0.37-0.60$ & 19.6 & $-60(-94$ to 16$)$ & $-19(-36$ to 5$)$ & 54 \\
\hline Lundell et al ${ }^{13}$ & 0.53 & $0.43-0.62$ & 14.9 & -14 ( -34 to 32$)$ & $-4(-15$ to 11$)$ & 16 \\
\hline Wessel et $\mathrm{al}^{14}$ & 0.45 & $0.35-0.54$ & 17.1 & $12(-17$ to 64$)$ & $4(-7$ to 17$)$ & 18 \\
\hline
\end{tabular}

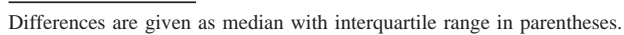

$\mathrm{CCC}=$ concordance correlation coefficient

An alternative model was constructed using minute ventilation, a value obtained from the breath-to-breath analysis system (model 3). In this case, resting $\dot{\mathrm{VO}}_{2}=$ $-142.92+0.52 \times$ heart rate (beats $/ \mathrm{min})+126.84 \times \mathrm{BSA}$ $\left(\mathrm{m}^{2}\right)+14.68 \times$ minute ventilation $(\mathrm{L})$. The $\mathrm{R}^{2}$ for this model was 0.68 (adjusted $\mathrm{R}^{2}$ : 0.68).

\section{Comparison of the New Models to Predict $\dot{\mathrm{V}}_{2}$ with Established Ones}

In the validation cohort, we compared our 3 models with 7 other available formulae that estimate resting $\dot{\mathrm{V}}_{2}$ (Table 4). We used the CCC, coefficient of variation, absolute and percentage difference, as well as Bland-Altman analysis. The CCCs of our 3 models (particularly models 1 and 3) were higher than others. The coefficients of variation as wells as the percentage differences between measured and estimated $\dot{\mathrm{V}}_{2}$ were lower for our models as well as the formulae by Bergstra et al, ${ }^{8}$ Lundell et al, ${ }^{13}$ and Wessel et al ${ }^{14}$ Bland-Altman analyses for model 1 and the formulae by Bergstra et al, ${ }^{8}$ Lundell et al, ${ }^{13}$ and Wessel et $\mathrm{al}^{14}$ are presented in Figure 1. All plots showed a proportional difference, because they tend to overestimate lower $\dot{\mathrm{V}}_{2}$ values and underestimate higher $\dot{\mathrm{V}}_{2}$ determinations.

\section{Characteristics of the Subjects Who Had $>25 \%$ Difference Between Estimated (Model 1) and Measured $\dot{\mathrm{V}}_{2}$}

Subjects who had $\geq 25 \%$ difference between the measured and estimated resting $\mathrm{V}_{2}$ (model 1) were older (63 \pm 15 vs $50 \pm 18 \mathrm{y}, P=.004)$ and had shorter stature $(163 \pm 10$ vs $169 \pm 10 \mathrm{~cm}, P=.02)$, lower measured MVV ( $82 \pm 40$ vs $110 \pm 44 \mathrm{~L}, P=.02)$, and higher heart rate $(91 \pm 17$ vs $81 \pm 14$ beats/min, $P=.07)$ than those with a small difference. No arterial blood gas or spirometric differences were noted between these groups. The addition of age or $\log _{\mathrm{e}}$ (age), height, or MVV to our models did not improve the $\mathrm{R}^{2}$.

\section{Discussion}

In the present study, we noted a poor accuracy between the measured and estimated $\dot{\mathrm{V}}_{2}$ in subjects with respiratory symptoms. Hence, we assessed the impact of a variety of factors on the measured $\dot{\mathrm{V}}_{2}$ and developed 3 models that included a selection of respiratory parameters $\left(\mathrm{F}_{\mathrm{IO}_{2}}\right.$, breathing frequency, or minute ventilation) that unexpectedly did not incorporate arterial blood gas or spirometric determinations. Even though our models performed better than other formulae in predicting $\mathrm{V}_{2}$ in this particular population, the limits of agreement were wide, particularly in older individuals with shorter stature, higher heart rate, and lower MVV.

Oxygen consumption is an essential measurement for the calculation of cardiac output by the accepted standard, Fick methodology; however, in the cardiac catheterization laboratories, $\dot{\mathrm{V}}_{2}$ is commonly estimated instead of measured, given that it is time-consuming and requires especial equipment (ie, breath-by-breath metabolic cart analysis) and expertise. As a result, in clinical practice, $\mathrm{V}_{\mathrm{O}_{2}}$ is often estimated by a variety of equations that generally use a combination of variables such as BSA, age, gender, and heart rate. ${ }^{8,9,11}$

Several investigators have noted poor agreement between measured and estimated $\dot{\mathrm{V}}_{2}$ in different groups of adult patients. ${ }^{1,2,20-24}$ In large part, this is due to marked differences between the population in which the formulae were derived and the characteristics of the cohort studied. 


\section{Estimating OXYGEn CONSUMPTION}
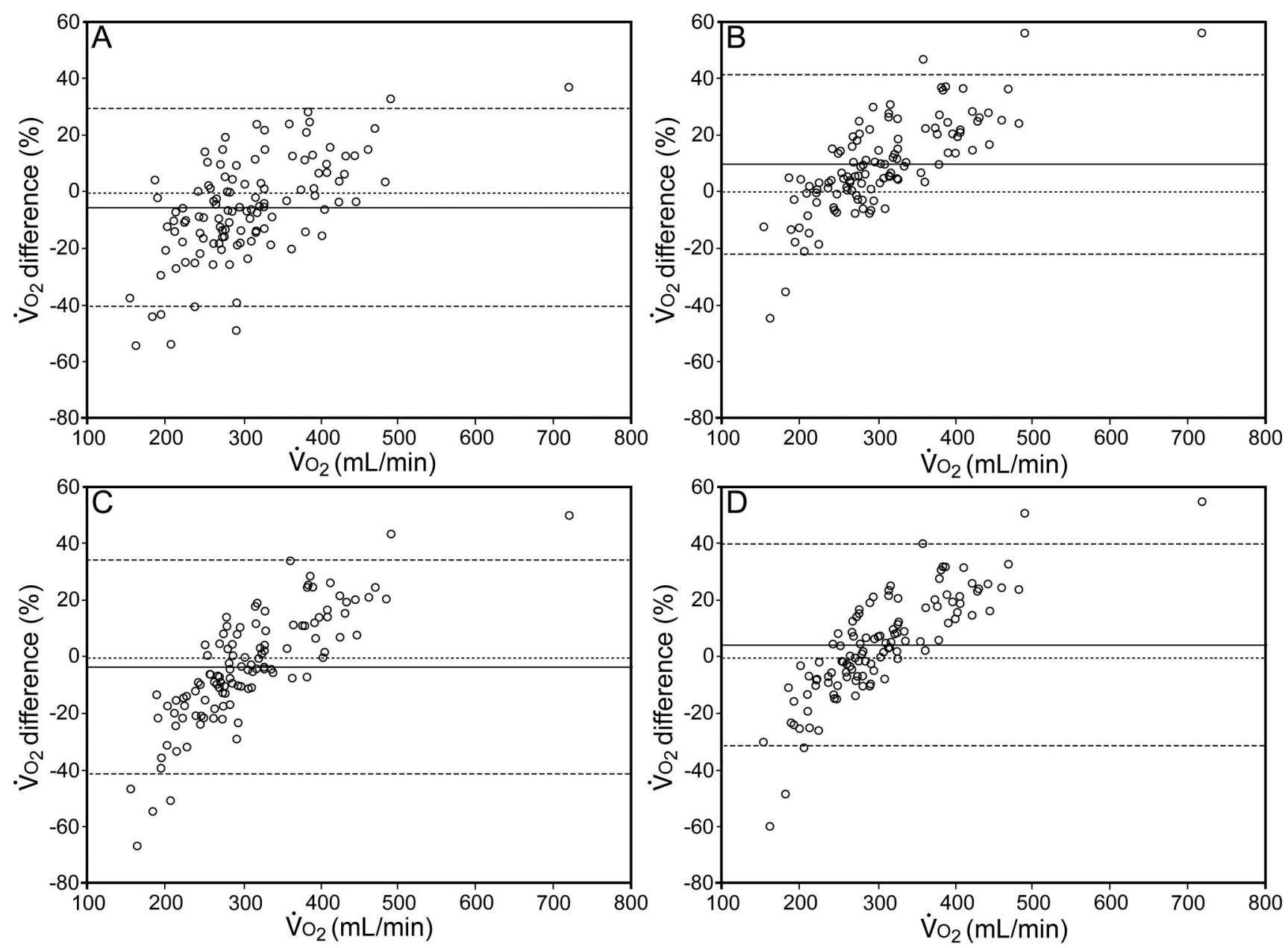

Fig. 1. Bland-Altman analyses between measured $\dot{\mathrm{V}}_{2}$ and the percentage difference between measured and estimated $\dot{\mathrm{V}}_{2}$. A: Proposed model 1 (mean difference: $-5.7 \%$, limit of agreement: $-40.4+29.1 \%$ ). B: Bergstra et al8 (mean difference: $9.7 \%$, limit of agreement: $-22+41.3 \%)$. C: Lundell et al ${ }^{13}$ (mean difference:-3.3\%, limit of agreement: $\left.-41.3+34.7 \%\right)$. D: Wessel et al ${ }^{14}$ (mean difference: $4.4 \%$, limit of agreement: $-31.2+40 \%)$. Solid horizontal lines indicate the mean; dashed horizontal lines indicate \pm 1.96 SD.

In fact, many factors can affect the measured $\mathrm{V}_{2}$ including age, ${ }^{8,11}$ gender, ${ }^{8,11,13,23,25} \mathrm{BSA},{ }^{8,11,13,23,25}$ fat-free mass, heart rate, $11,13,25$ degree of sedation, $, 914,25$ temperature (of the patient and environment), ${ }^{25}$ time of day, prior food intake, level of activity, ${ }^{25}$ and position. ${ }^{9}$

Although several parameters were associated with resting $\mathrm{V}_{2}$ in multivariate models, only BSA, gender, heart rate, breathing frequency, need for supplementary $\mathrm{O}_{2}$, and minute ventilation were significant predictors. Because $\dot{\mathrm{V}}_{2}$ directly depends on the body size of a person, BSA is the most commonly used variable in available equations. In fact, BSA was used in all but two ${ }^{10,12}$ of the tested formulae for resting $\dot{\mathrm{V}}_{2}$ estimation. The formulae proposed by Krovetz et al ${ }^{10}$ uses height and weight and the equation by Lindahl ${ }^{12}$ only weight. In our study, BSA area was selected for our models instead of height and/or weight.

Men have a higher $\dot{\mathrm{V}}_{2}$ than women, given the higher fat-free mass. Therefore, gender was selected in three ${ }^{8,11,13}$ out of the 7 formulae tested. Similarly, heart rate, an in- dicator of stress that changes in relation to the metabolic rate, was used in 2 out of the 7 equations. Breathing frequency, need for supplementary $\mathrm{O}_{2}$, and minute ventilation were not included in prior equations that estimate resting $\dot{\mathrm{V}}_{2}$, likely because these parameters are more applicable to our particular group of subjects with respiratory symptoms. It is important to consider that, immediately before cardiopulmonary exercise testing or cardiac catheterization, patients are not in a strictly basal state as they may be anxious, a condition that may lead to an increase in minute ventilation, heart rate, and $\dot{\mathrm{V}}_{2} \cdot{ }^{2}$

Age, as $\log _{\mathrm{e}}$ (age), was used in two ${ }^{8,11}$ formulae, obtained in cohorts that included children and adults. In the present study, we also noted that age was indirectly associated with $\dot{\mathrm{V}}_{2} / \mathrm{kg}$; however, age or $\log _{\mathrm{e}}$ (age) was not selected in any of our 3 multivariate models that predict $\dot{\mathrm{V}}_{2}$. Furthermore, specific determinations of general value in pulmonary patients, that is, arterial blood gases or spirometry, did not add prognostic value. 


\section{Estimating OXYGEn CONSUMPTION}

The 3 models presented in our study had wide limits of agreement and were not able to explain more than $68 \%$ of the $\dot{\mathrm{V}}_{2}$ variance. In addition, adding parameters obtained from arterial blood gases and/or pulmonary function tests did not improve the performance of the equations to predict $\dot{\mathrm{V}}_{2}$, a fact that negated our working hypothesis. This could reflect that $\mathrm{F}_{\mathrm{IO}_{2}}$ (model 1), breathing frequency (model 2), and minute ventilation (model 3 ) are better and probably more comprehensive estimates of $\dot{\mathrm{V}}_{2}$ than other more specific parameters obtained from spirometry or arterial blood gases.

In general, the formulae that estimate $\dot{\mathrm{V}}_{2}$ are associated with systematic error as they tend to underestimate the higher $\dot{\mathrm{V}}_{2}$ values and overestimate the lower determinations. This is relevant because differences between the measured and estimated $\dot{\mathrm{V}}_{2}$ of $\geq 25 \%$ may result in large errors in the determination of $\mathrm{Q}$ and calculation of dependent variables. In our study, we observed that the estimated $\mathrm{V}_{2}$ was mostly inaccurate in older individuals with shorter stature, higher heart rate, and lower MVV. The reasons for the greater discrepancies between measured and estimated $\dot{\mathrm{V}}_{2}$ in this group of subjects remain unclear. A potential explanation include a nonlinear relationship between $\dot{\mathrm{V}}_{2}$ and age, height, MVV, or heart rate. It is possible that, due to the limited number of subjects at the end of these spectra, our model was not sensitive enough to detect this nonlinear association. Future studies testing particular subgroups of subjects may be of value to refine our equations.

The $\dot{\mathrm{V}}_{2}$ variance not captured in our study might be explained by variables that we did not measure, such as fat-free mass, core temperature, and general level of activity. It is also likely that there are unknown factors that might be responsible for the $\dot{\mathrm{V}}_{2}$ variation. Given that $\dot{\mathrm{V}}_{2}$ varies greatly and estimations are still generally inaccurate, we support the direct measurement of $\dot{\mathrm{V}}_{2}$ instead of its estimation. It is also important to point out that $\dot{\mathrm{V}}_{2}$ varies in patients with sepsis, ${ }^{26,27}$ hypovolemia, ${ }^{28}$ pulmonary hypertension, ${ }^{29}$ congestive heart failure, ${ }^{30}$ or COPD, ${ }^{31}$ both at baseline and with treatment. ${ }^{32}$ Thus, current formulae are likely inaccurate in these groups of patients.

Our study has limitations: (1) the results are only applicable to nonsedated patients at rest in a sitting position with respiratory symptoms and/or conditions, (2) body temperature and fat-free mass were not measured at the time of $\dot{\mathrm{O}}_{2}$ determination, and (3) we cannot exclude potential bias due to the retrospective nature of our study; however, cardiopulmonary exercise studies were performed by a few experienced respiratory therapists under similar conditions and following a prespecified protocol. Notwithstanding these limitations, our study emphasizes the lack of accuracy of formulae to predict $\dot{\mathrm{V}}_{\mathrm{O}_{2}}$ and is the first to generate different models to estimate resting $\mathrm{V}_{2}$ in sub- jects with respiratory symptoms or conditions, and to compare them with available formulae.

\section{Conclusions}

We developed more accurate formulae to predict oxygen consumption in the group of subjects who underwent cardiopulmonary exercise testing for respiratory symptoms and/or conditions. Arterial blood gases and spirometric variables did not significantly improve the predictive equations.

\section{ACKNOWLEDGMENTS}

This study would not have been possible without the hard work of Cleveland Clinic respiratory therapists who performed the cardiopulmonary exercise test and contributed to the database.

\section{REFERENCES}

1. Narang N, Thibodeau JT, Levine BD, Gore MO, Ayers CR, Lange RA, et al. Inaccuracy of estimated resting oxygen uptake in the clinical setting. Circulation 2014;129(2):203-210.

2. Kendrick AH, West J, Papouchado M, Rozkovec A. Direct Fick cardiac output: are assumed values of oxygen consumption acceptable? Eur Heart J 1988;9(3):337-342.

3. American Thoracic Society, American College of Chest Physicians. ATS/ACCP Statement on cardiopulmonary exercise testing. Am J Respir Crit Care Med 2003;167(2):211-277.

4. Du Bois D, Du Bois EF. Clinical Calorimetry. A formula to estimate the approximate surface area if height and weight be known. Arch Intern Med 1916;17(6):863-871.

5. Miller MR, Hankinson J, Brusasco V, Burgos F, Casaburi R, Coates A, et al. Standardisation of spirometry. Eur Respir J 2005;26(2):319338.

6. Vestbo J, Hurd SS, Agusti AG, Jones PW, Vogelmeier C, Anzueto A, et al. Global strategy for the diagnosis, management, and prevention of chronic obstructive pulmonary disease: GOLD executive summary. Am J Respir Crit Care Med 2013;187(4):347-365.

7. American Thoracic Society. Lung function testing: selection of reference values and interpretative strategies. Am Rev Respir Dis 1991; 144(5):1202-1218.

8. Bergstra A, van Dijk RB, Hillege HL, Lie KI, Mook GA. Assumed oxygen consumption based on calculation from dye dilution cardiac output: an improved formula. Eur Heart J 1995;16(5):698-703.

9. Dehmer GJ, Firth BG, Hillis LD. Oxygen consumption in adult patients during cardiac catheterization. Clin Cardiol 1982;5(8):436440.

10. Krovetz LJ, Goldbloom S. Normal standards for cardiovascular data. I. Examination of the validity of cardiac index. Johns Hopkins Med J 1972;130(3):174-186.

11. LaFarge CG, Miettinen OS. The estimation of oxygen consumption. Cardiovasc Res 1970;4(1):23-30.

12. Lindahl SG. Oxygen consumption and carbon dioxide elimination in infants and children during anaesthesia and surgery. $\mathrm{Br} \mathrm{J}$ Anaesth 1989;62(1):70-76.

13. Lundell BP, Casas ML, Wallgren CG. Oxygen consumption in infants and children during heart catheterization. Pediatr Cardiol 1996; 17(4):207-213.

14. Wessel HU, Rorem D, Muster AJ, Acevedo RE, Paul MH. Continuous determination of oxygen uptake in sedated infants and children during cardiac catheterization. Am J Cardiol 1969;24(3):376-385. 


\section{Estimating OXYGEn CONSUMPTION}

15. Kuhn M. Building predictive models in R using the caret package. J Stat Software 2008;28(5):1-26.

16. Akaike $\mathrm{H}$. A new look at the statistical model identification. IEEE T Automat Contr 1974;19(6):716-723.

17. Lin LI. A concordance correlation coefficient to evaluate reproducibility. Biometrics 1989;45(1):255-268.

18. Bland JM, Altman DG. Measuring agreement in method comparison studies. Stat Methods Med Res 1999;8(2):135-160.

19. Krouwer JS. Why Bland-Altman plots should use $X$, not $(Y+X) / 2$ when $X$ is a reference method. Stat Med 2008;27(5):778-780.

20. Wolf A, Pollman MJ, Trindade PT, Fowler MB, Alderman EL. Use of assumed versus measured oxygen consumption for the determination of cardiac output using the Fick principle. Cathet Cardiovasc Diagn 1998;43(4):372-380.

21. Narang N, Gore MO, Snell PG, Ayers CR, Lorenzo S, CarrickRanson G, et al. Accuracy of estimating resting oxygen uptake and implications for hemodynamic assessment. Am J Cardiol 2012; 109(4):594-598.

22. Fakler U, Pauli C, Hennig M, Sebening W, Hess J. Assumed oxygen consumption frequently results in large errors in the determination of cardiac output. J Thorac Cardiovasc Surg 2005;130(2): 272-276.

23. Gertz ZM, McCauley BD, Raina A, O'Donnell W, Shellenberger C, Willhide $\mathbf{J}$, et al. Estimation of oxygen consumption in elderly patients with aortic stenosis. Catheter Cardiovasc Interv 2014;83(1): E128-133.

24. Fares WH, Blanchard SK, Stouffer GA, Chang PP, Rosamond WD, Ford HJ, Aris RM. Thermodilution and Fick cardiac outputs differ: impact on pulmonary hypertension evaluation. Can Respir J 2012; 19(4):261-266.

25. Fixler DE, Carrell T, Browne R, Willis K, Miller WW. Oxygen consumption in infants and children during cardiac catheterization under different sedation regimens. Circulation 1974;50(4): 788-794.

26. Haupt MT, Gilbert EM, Carlson RW. Fluid loading increases oxygen consumption in septic patients with lactic acidosis. Am Rev Respir Dis 1985;131(6):912-916.

27. Bihari D, Smithies M, Gimson A, Tinker J. The effects of vasodilation with prostacyclin on oxygen delivery and uptake in critically ill patients. N Engl J Med 1987;317(7):397-403.

28. Kaufman BS, Rackow EC, Falk JL. The relationship between oxygen delivery and consumption during fluid resuscitation of hypovolemic and septic shock. Chest 1984;85(3):336-340.

29. Mohsenifar Z, Jasper AC, Koerner SK. Relationship between oxygen uptake and oxygen delivery in patients with pulmonary hypertension. Am Rev Respir Dis 1988;138(1):69-73.

30. Mohsenifar Z, Amin D, Jasper AC, Shah PK, Koerner SK. Dependence of oxygen consumption on oxygen delivery in patients with chronic congestive heart failure. Chest 1987;92(3):447-450.

31. Brent BN, Matthay RA, Mahler DA, Berger HJ, Zaret BL, Lister G. Relationship between oxygen uptake and oxygen transport in stable patients with chronic obstructive pulmonary disease: physiologic effects of nitroprusside and hydralazine. Am Rev Respir Dis 1984; 129(5):682-686.

32. Dantzker DR. Oxygen transport and utilization in ARDS. Eur Respir J Suppl 1990;11:485s-489s. 